\title{
Recurrent sessile serrated adenoma invading the site of previous appendectomy effectively resected by endoscopic submucosal dissection with double-clip and rubber band traction
}

Endoscopic submucosal dissection (ESD) became the treatment of choice for colorectal superficial neoplastic lesions larger than $25 \mathrm{~mm}$ to achieve complete and curative resection, avoiding unnecessary surgery [1]. Double-clip and rubber band traction (DCT-ESD) was demonstrated to be a useful tool for Western endoscopists, allowing a better, faster, and safer procedure [2]. Moreover, for challenging lesions such as those on the site of previous appendectomy, or recurrent lesions, DCT-ESD allowed a promising outcome as well $[3,4]$.

We report the case of a 67-year-old man who underwent endoscopic mucosal resection of a 13-mm sessile serrated adenoma on the site of previous appendectomy in 2014. In 2019, a recurrent lesion was found, which had been incompletely resected by EMR. The patient was then referred to our center.

During the procedure, we identified a hemoclip placed within the lesion. We decided to perform DCT-ESD to achieve en bloc resection without removing the clip, to avoid any defect on the lesion ( Video 1). After submucosal injection, there was a poor lifting sign, which indicated severe fibrosis beneath the lesion ( Fig.1). Good traction was achieved after the placement of our traction system. Submucosal dissection was then performed very carefully and slowly. Despite the two holes on the cut specimen, we could successfully finish the resection, with a $25 \times 30 \mathrm{~mm}$ en bloc specimen in 30 minutes, without any adverse events. Six clips (two during submucosal dissection and four at the end of the procedure) were used to prevent any delayed perforation or bleeding ( Fig. 2, $>$ Fig.3). Pathological examination revealed complete $R 0$ resection of a sessile serrated adenoma without any dysplasia.

Thanks to our traction system, this doubly difficult lesion (appendiceal and recurrent lesion) could be effectively re-

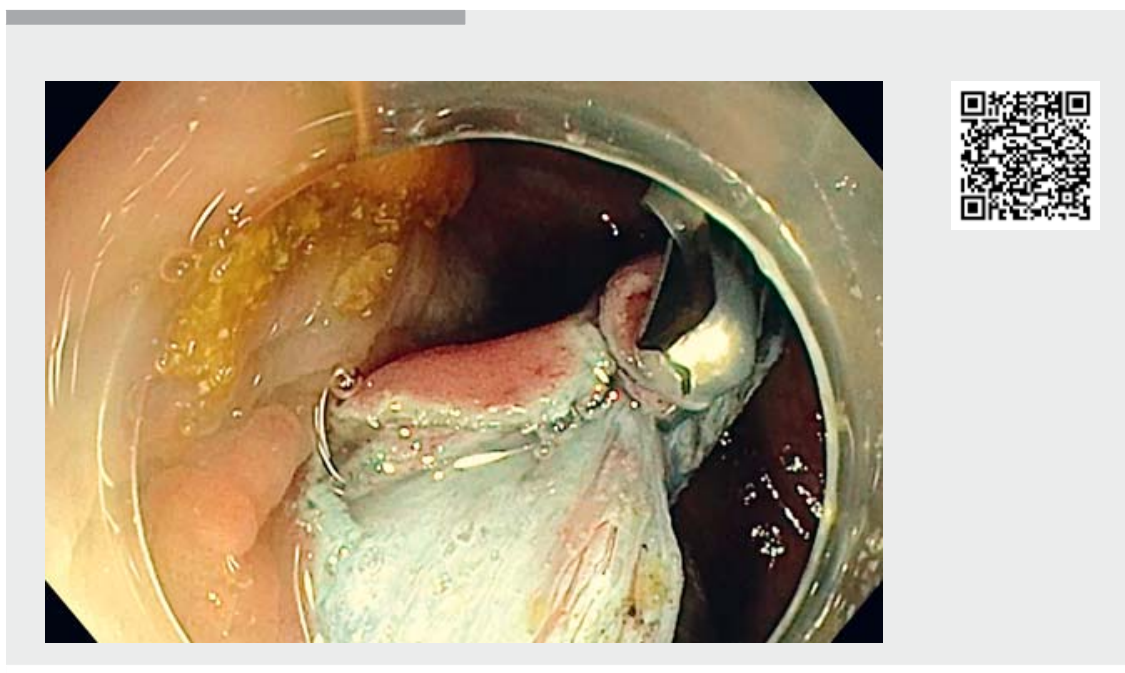

Video 1 Recurrent sessile serrated adenoma invading the site of previous appendectomy effectively resected by endoscopic submucosal dissection with double-clip and rubber band traction.
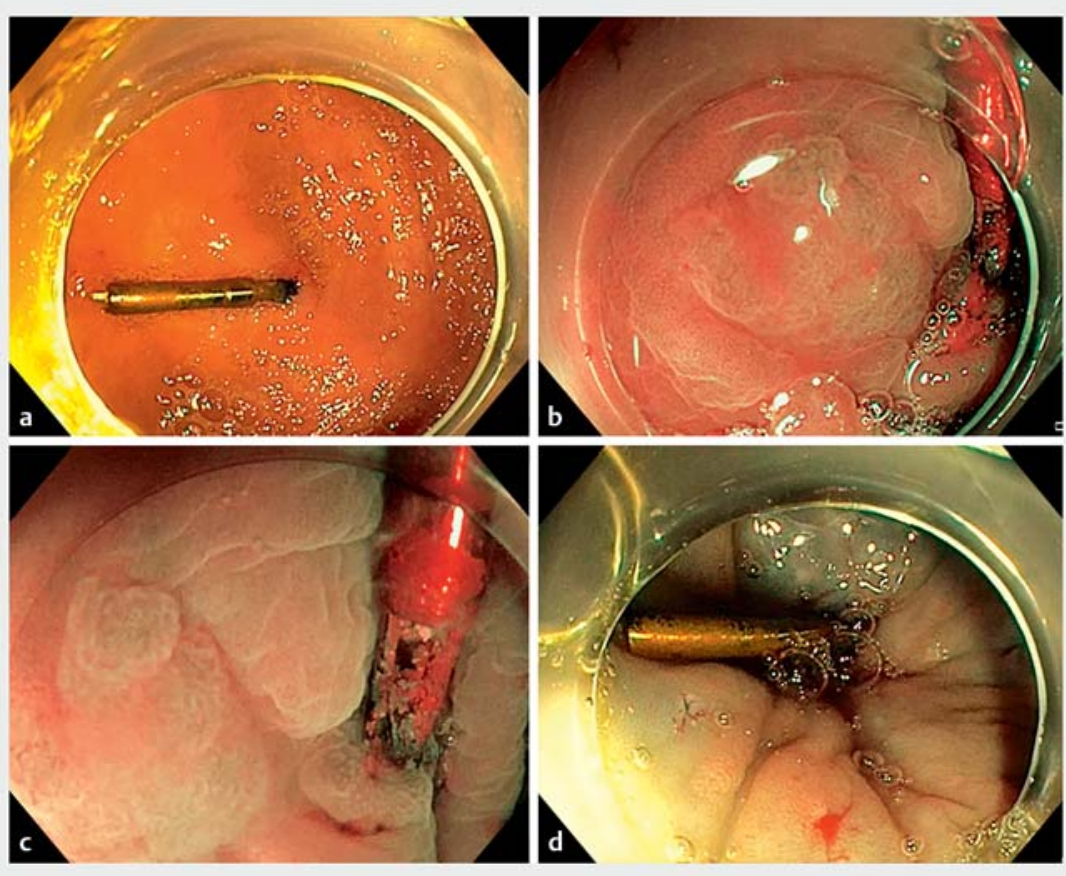

- Fig. 1 Recurrent sessile serrated adenoma (SSA) on the site of previous appendectomy. a A hemoclip was seen within the resection site. $\mathbf{b}$ SSA under narrow-band imaging (NBI) examination; c SSA underwater and NBI examination. $\mathbf{d}$ Poor lifting sign after submucosal injection. 

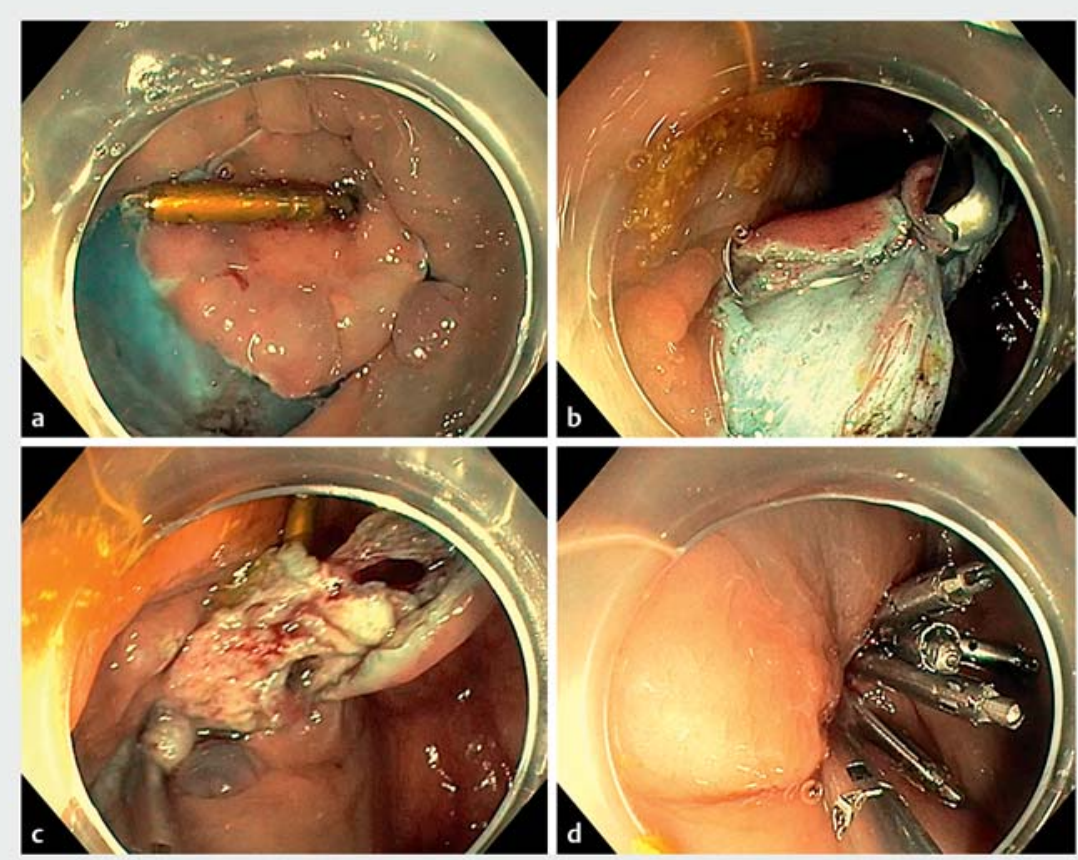

- Fig. 2 Endoscopic submucosal dissection with double-clip and rubber band traction. a Circumferential incision. b Good traction achieved after placement of the traction system. c Two holes on the cut specimen. $\mathbf{d}$ Six clips placed on the resection site.

sected endoscopically. Clip placement during dissection was particularly facilitated by our traction system by creating a better plane for clip positioning. Thus, this strategy remains promising in our center and potentially for other types of challenging lesions.

Endoscopy_UCTN_Code_TTT_1AQ_2AD

\section{Competing interests}

The authors declare that they have no conflict of interest.

The authors

Borathchakra Oung ${ }^{1,2}$, Jérémie Jacques ${ }^{3}$, Jérôme Rivory ${ }^{4}$, Rémi Systchenko ${ }^{5}$, Thierry Ponchon $^{4}$, Mathieu Pioche ${ }^{4}$

1 Faculty of Medicine, University of Health Sciences, Phnom Penh, Cambodia

2 Cambodian Association of Gastrointestinal Endoscopy (CAGE), Phnom Penh Cambodia

3 Department of Endoscopy and Gastroenterology, Dupuytren University Hospital, Limoges, France
4 Department of Endoscopy and Gastroenterology, Pavillon L, Edouard Herriot Hospital, Lyon, France

5 Gastroenterology and Hepatology, Charcot Clinic, Lyon, France

\section{Corresponding author}

\section{Mathieu Pioche, MD}

Endoscopy Unit - Digestive Disease Department, Pavillon L, Edouard Herriot Hospital, 69437 Lyon Cedex, France Fax: +33-4-72110147

mathieu.pioche@chu-lyon.fr

\section{References}

[1] Pimentel-Nunes P, Dinis-Ribeiro M, Ponchon $T$ et al. Endoscopic submucosal dissection: European Society of Gastrointestinal Endoscopy (ESGE) guideline. Endoscopy 2015; 47: 829-854

[2] Jacques ], Charissoux A, Bordillon P et al. High proficiency of colonic endoscopic submucosal dissection in Europe thanks to countertraction strategy using a double clip and rubber band. Endosc Int Open 2019; 7: E1166-E1174

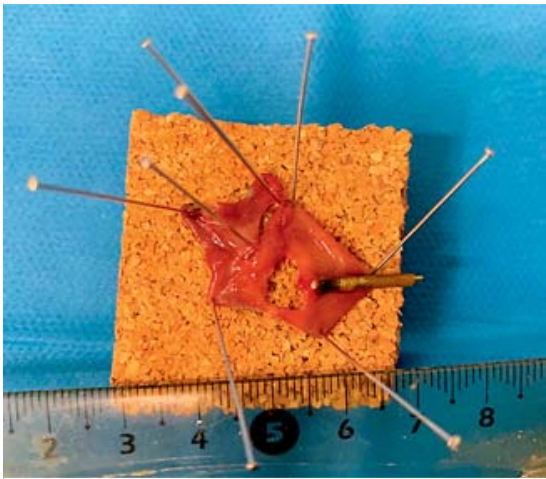

- Fig. 3 The $25 \times 30 \mathrm{~mm}$ resected specimen stretched onto a cork board.

[3] Oung B, Chabrun E, Subtil C et al. Traction strategy with clips and rubber band allows complete en bloc endoscopic submucosal dissection of sessile serrated adenoma/ polyp invading the site of previous appendectomy. Endoscopy 2019; 51: E166-E168

[4] Faller J, Jacques J, Oung B et al. Endoscopic submucosal dissection with double clip and rubber band traction for residual or locally recurrent colonic lesions after previous endoscopic mucosal resection. Endoscopy 2020. doi:10.1055/a-1104-5210

\section{Bibliography}

DOI https://doi.org/10.1055/a-1133-4260

Published online: 27.3.2020

Endoscopy 2020; 52: E366-E367

(c) Georg Thieme Verlag KG

Stuttgart · New York

ISSN 0013-726X

\section{ENDOSCOPY E-VIDEOS \\ https://eref.thieme.de/e-videos}

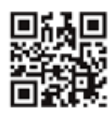

Endoscopy E-Videos is a free access online section, reporting on interesting cases and new techniques in gastroenterological endoscopy. All papers include a high quality video and all contributions are freely accessible online.

This section has its own submission website at https://mc.manuscriptcentral.com/e-videos 